\title{
Epidemiological Study of Various Skin Diseases and Prescription Pattern of Drugs in Dermatological OPD in Khammam Region
}

\author{
T Praveen Kumar ${ }^{1, *}$, S Shivani ${ }^{2}$ \\ ${ }^{1}$ Assistant Professor, Department of Pharmaceutics, Anurag Pharmacy College, JNTU Hyderabad, Ananthagiri, Telangana, INDIA. \\ ${ }^{2}$ Pharm.D, Browns College of Pharmacy, Kakatiya University, Khammam, Telangana, INDIA.
}

Background: The study is conducted to identify the epidemiology of various skin diseases in and around Khammam (District Government Hospital, Khammam) and to assess the prescription pattern of drugs in dermatological OPD. Objectives: The main objective is to identify the pattern of drugs used in skin OPD and also to know distribution of clinical types according to age, gender, socio-economic status and disease. Methods: The study was designed to be a prospective observational Study. It was conducted in out-patient department of Dermatology, District headquarters government hospital, Khammam, over a period of 6 months from November 2018 to April 2019 which includes 300 Cases. Patients are randomly enrolled in the study based on inclusion and exclusion criteria. Specially designed Annexure-I (Patient standard data collection form) is used to obtain the data required for the study. Results: In our study, we screened 300 patients out of them 151 (50.3\%) were male and 149 (49.7\%) were females. It was found that bacterial diseases accounts $43(14.3 \%), 59(19.6 \%)$ are fungal diseases, 11 $(3.6 \%)$ are viral diseases, $85(28.3 \%)$ are parasitic diseases, $45(34 \%)$ are inflammatory skin diseases and 57 $(19 \%)$ are other category of skin diseases. Conclusion: The major skin diseases identified from our study were scabies, tinea corporis, eczema, acne and urticaria in which male patients were more susceptible. The most common class of drugs prescribed in our hospital includes Antihistamines (23.8\%), Antacid (20.9\%), Antibiotics $(20.8 \%)$, Antifungals (8.4\%), Antiparasitic $(8.3 \%)$ and Corticosteroids (5\%). The infectious diseases were more common $(65 \%)$ followed by non-infectious diseases (34\%). Public awareness regarding personal hygiene and healthy living is necessary to reduce the burden of skin diseases and for improved quality of life in people especially in rural areas and developing nations.
\end{abstract}

Key words: Bacterial Diseases, Dermatology, Prescription Pattern, Personal Hygiene, Scabies, Tinea corporis.

\section{INTRODUCTION}

Healthy and attractive skin plays an important role in people's self-esteem. ${ }^{1}$ Skin diseases affect all age groups from neonates to the elderly. ${ }^{2}$ Skin constitutes the largest organ of human body and is exposed to injury by various intrinsic factors such as metabolic, genetic and immunological and extrinsic factors such as environmental, chemical, infectious agents. Many systemic diseases are also identified by their dermatological manifestations. ${ }^{3,4}$ The skin diseases have detrimental effect on quality of life of population by increasing the suffering in terms of physical, social, psychological and financial burden as most of the skin diseases are chronic and requires longer duration of treatment. In developing countries like
India other than hot and humid conditions, low hygiene, poor access to water, overcrowding, high interpersonal contact also plays significant etiological role for certain skin diseases like pyoderma, scabies and fungal infections..$^{5-9}$

In India, there are many problems in prescription pattern of drugs like overuse of multivitamins, irrational drug combinations, unnecessary use of antibacterial in fungal conditions and prescribing drugs of same class. ${ }^{10,11}$ It also contributes to the emergence of antimicrobial resistance. Dermatologists account for almost $5 \%$ of antibiotic prescriptions worldwide and most of the conditions require prolonged treatment. ${ }^{12,13}$
DOI: 10.5530/ijopp.13.1.7

Address for correspondence: T. Praveen Kumar, Assistant Professor, Department of Pharmaceutics, Anurag Pharmacy College, Ananthagiri, Kodad Suryapet, Telangana, INDIA.

Phone no: +91-9100337332 Email Id: praveensuri1@gmail. com

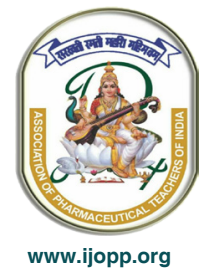


Improved quality of life can be enhanced by setting standards in medical treatment at all levels of the health care delivery system. Setting standards and assessing the quality of care through performance review should become part of everyday clinical practice. ${ }^{14}$ Prescribing habits make medical care rational and cost effective. Such analysis not only improves the standards of medical treatment but also supports in the identification of drug use related problems such as, drug-drug interaction, polypharmacy and adverse drug reaction. ${ }^{15,16}$ Ignorance on seriousness of the disease and improper medication worsens the health condition. ${ }^{17}$ More than $80 \%$ of the population suffering from skin problems may not seek medical help.

\section{METHODS}

The study was designed to be a prospective observational Study. It was conducted in out-patient department of Dermatology, District headquarters government hospital, Khammam, Telangana. The study was conducted over a period of 6 months from November 2018 to April 2019 which includes 300 Cases. Patients are randomly enrolled in the study based on inclusion and exclusion criteria. All age groups of both male, female gender and patients who have history of skin infections have been included in the study. Pregnant, lactating women and patients suffering from chronic diseases and genetic conditions are excluded from the study. A specially designed Annexure-I (Patient standard data collection form) is used to obtain the data required for the study.

\section{Study procedure}

The patients were prospectively selected for the study by simple random sampling method from OP Dermatology Department. The patients were categorized into male and female. Further the patients are classified according to their age group, social status and religion. Then the patients were categorized according to their disease condition. Then the drugs in the prescription were classified according to the pharmacological classification. The prevalence of skin diseases and pattern of prescribed drugs were identified.

\section{RESULTS}

A Prospective observational study was conducted in a Government district headquarters hospital, Khammam for a period of 6 months. A total of 300 patients were recruited under inclusion and exclusion criteria.

\section{Patient distribution based on gender}

In our study, we screened 300 cases for skin related problems. Out of 300 patients 151 (50.3\%) were male and 149 (49.7) were females, results shown in Table 1 and Figure 1.

\section{Patient categorization based on age}

Out of 300 patients, 57 (19\%) patients were found between the age group of $0-10,60(20 \%)$ were in between 11-20, $50(16.6 \%)$ were in between 21-30, $47(15.6 \%)$ were in between 31-40, 43 (14.3\%) were in between 41-50, 24 $(8 \%)$ were in between $51-60,13(4.3 \%)$ were in between 61-70 and $6(2 \%)$ were in between 71-80. The results were shown in Table 2 and Figure 2.

\section{Patient distribution based on social status}

Out of 300 patients, 132 (44\%) patients belong to low status, $162(54 \%)$ patients belong to middle status and $6(2 \%)$ patients belong to high status. The results were shown in Table 3 and Figure 3.

\section{Distribution of diseases among the study population}

Out of 300 patients, bacterial diseases have been found to be 43 (14.3\%), 59 (19.6\%) have been found for fungal diseases, $11(3.6 \%)$ have been found for viral diseases, $85(28.3 \%)$ have been found for parasitic diseases, 45 (34\%) have been found for inflammatory skin diseases and $57(19 \%)$ have been found for other category of skin diseases. The results were summarized in Table 4 and Figure 4.

\section{Based on pharmacological classification}

A total of 1053 medicines were prescribed for 300 patients. Anti-histamines were the most prescribed drug (23.8\%) among the population, followed by other category of drugs as shown in the Table 5 and Figure 5.

\section{Disease Wise Distribution}

\section{Bacterial diseases categorization}

Out of 43 bacterial diseases, Acne has been found to be highest in number $21(48.8 \%)$ followed by bullous impetigo $14(32.5 \%)$, furuncle $3(6.9 \%)$, folluculitis 3 $(6.9 \%)$ and leprosy $2(4.6 \%)$. The results were shown in Table 6 and Figure 6.

\section{Fungal diseases categorization}

Out of 59 fungal diseases, Tinea corporis has been found to be highest in number 31 (52.8\%) followed by Pityriasis versicolor $14(23.7 \%)$, Tinea cruris 07 (11.8\%), Tinea facialis 03 (5.08\%), Seborrheic dermatitis $01(1.6 \%)$ and Pityriasis rosea $01(1.6 \%)$. The results were summarized in Table 7 and Figure 7. 
Table 1: Patient distribution based on gender.

\begin{tabular}{ccc} 
Gender & No. of Patients & Percentage (\%) \\
\hline Male & 151 & $50.3 \%$ \\
Female & 149 & $49.7 \%$ \\
Total & $\mathbf{3 0 0}$ & $\mathbf{1 0 0 \%}$ \\
\hline
\end{tabular}

Table 2: Patient Categorization Based on Age.

\begin{tabular}{ccccc} 
Age group & Male & Female & Total & Percentage (\%) \\
\hline $0-10$ & 27 & 30 & 57 & $19 \%$ \\
$11-20$ & 23 & 37 & 60 & $20 \%$ \\
$21-30$ & 31 & 19 & 50 & $16.6 \%$ \\
$31-40$ & 22 & 25 & 47 & $15.6 \%$ \\
$41-50$ & 21 & 22 & 43 & $14.3 \%$ \\
$51-60$ & 15 & 9 & 24 & $8 \%$ \\
$61-70$ & 7 & 6 & 13 & $4.3 \%$ \\
$71-80$ & 5 & 1 & 6 & $2 \%$ \\
Total & 151 & 149 & $\mathbf{3 0 0}$ & $\mathbf{1 0 0 \%}$ \\
\hline
\end{tabular}

Table 3: Patient distribution based on social status.

\begin{tabular}{ccc} 
Social Status & No. of Patients & Percentage (\%) \\
\hline Low & 132 & $44 \%$ \\
Middle & 162 & $54 \%$ \\
High & 6 & $2 \%$ \\
Total & $\mathbf{3 0 0}$ & $\mathbf{1 0 0 \%}$ \\
\hline
\end{tabular}

Table 4: Distribution of diseases among the study population.

\begin{tabular}{ccc}
\hline Type of Infection & $\begin{array}{c}\text { No. of } \\
\text { Patients }\end{array}$ & Percentage (\%) \\
\hline Bacterial diseases & 43 & $14.3 \%$ \\
Fungal diseases & 59 & $19.6 \%$ \\
Viral diseases & 11 & $3.6 \%$ \\
Parasitic diseases & 85 & $28.3 \%$ \\
Inflammatory skin diseases & 45 & $15 \%$ \\
Others & 57 & $19 \%$ \\
Total & $\mathbf{3 0 0}$ & $\mathbf{1 0 0 \%}$ \\
\hline
\end{tabular}

\section{Parasitic diseases categorization}

In our study, Scabies is the only parasitic disease of 85 cases reported. The results were shown in Table 8 and Figure 8.

\section{Viral diseases categorization}

Out of 11 viral diseases, Herpes zoster has been found to be highest in number, 4 (36.36\%) followed by Herpes

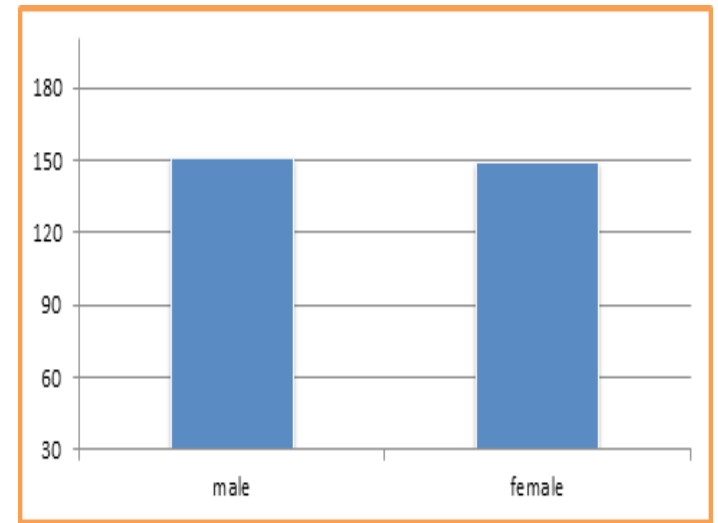

Figure 1: Patient distribution based on gender.

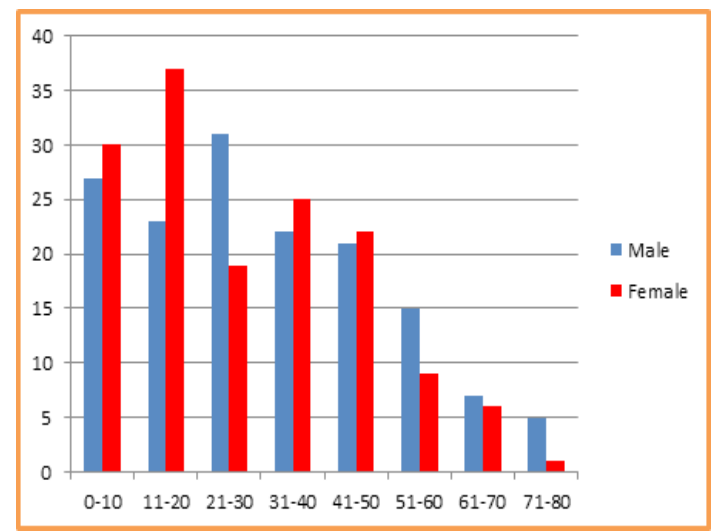

Figure 2: Patient categorization based on age.

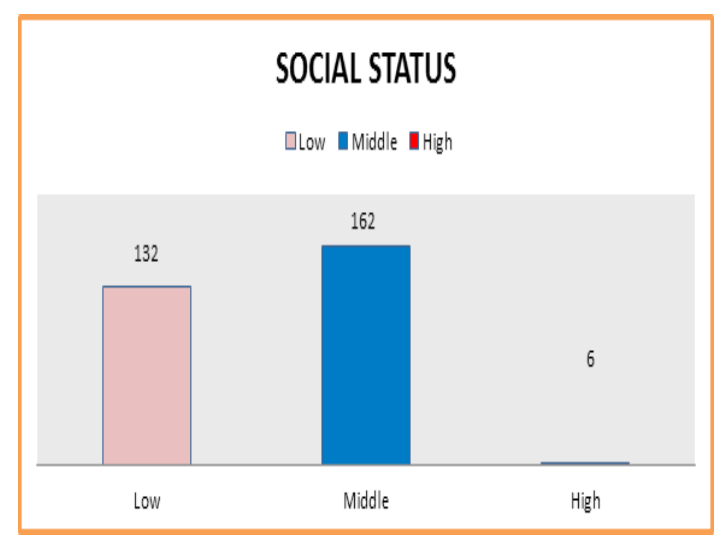

Figure 3: Patient Distribution Based on Social Status.

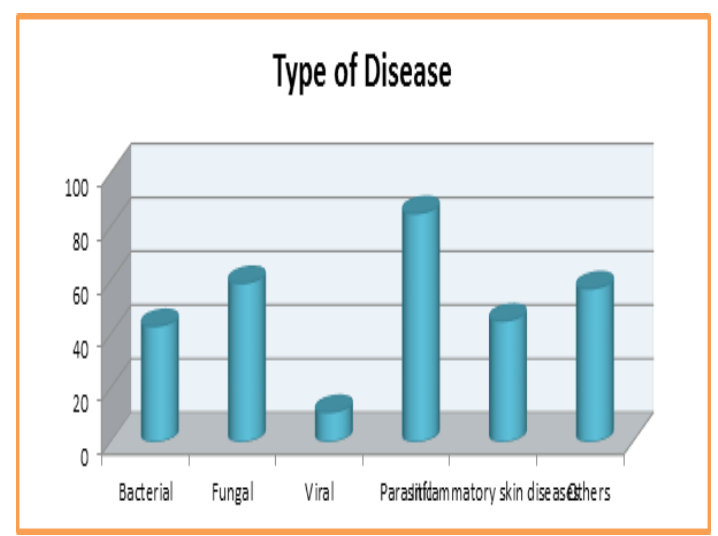

Figure 4: Distribution of diseases among the study population. 
Table 5: Medication categories prescribed for the study patient.

\begin{tabular}{ccc}
\hline Class of drug & No. of drugs & Percentage (\%) \\
\hline Anti-histamines & 251 & $23.8 \%$ \\
Antacid & 221 & $20.9 \%$ \\
Anti-bacterial & 220 & $20.8 \%$ \\
Anti-fungal & 89 & $8.4 \%$ \\
Anti-parasitic & 88 & $8.3 \%$ \\
Corticosteroid & 53 & $5.0 \%$ \\
Vitamin supplements & 36 & $3.4 \%$ \\
Keratolytics & 22 & $2.0 \%$ \\
Anti-amoebics & 19 & $1.8 \%$ \\
Analgesics & 17 & $1.6 \%$ \\
Emollients & 10 & $0.9 \%$ \\
Anti-inflammatory drugs & 07 & $0.6 \%$ \\
Anti-viral & 06 & $0.5 \%$ \\
Immunosuppressant's & 04 & $0.3 \%$ \\
Anti-leprotic drugs & 03 & $0.2 \%$ \\
Beta-blockers & 03 & $0.2 \%$ \\
Anti-oxidants & 02 & $0.1 \%$ \\
Lipid lowering drugs & 02 & $0.1 \%$ \\
& $\mathrm{~N}=1053$ & $100 \%$ \\
\hline
\end{tabular}

\section{Table 6: Bacterial diseases categorization.}

\begin{tabular}{ccc}
\hline Bacterial Disease & No. of cases & Percentage (\%) \\
\hline Acne & 21 & $48.8 \%$ \\
Bullous Impetigo & 14 & $32.5 \%$ \\
Furuncle & 03 & $6.9 \%$ \\
Folluculitis & 03 & $6.9 \%$ \\
Leprosy & 02 & $4.6 \%$ \\
Total & $\mathbf{4 3}$ & $\mathbf{1 0 0 \%}$ \\
\hline
\end{tabular}

\section{Table 7: Fungal diseases categorization.}

\begin{tabular}{ccc} 
Fungal Disease & No. of cases & Percentage (\%) \\
Tinea corporis & 31 & $52.8 \%$ \\
Pityriasis versicolor & 14 & $23.7 \%$ \\
Tinea cruris & 07 & $11.8 \%$ \\
Tinea facialis & 03 & $5.08 \%$ \\
Paronychia & 02 & $3.3 \%$ \\
Seborrheic dermatitis & 01 & $1.6 \%$ \\
Pityriasis rosea & 01 & $1.6 \%$ \\
Total & $\mathbf{5 9}$ & $\mathbf{1 0 0 \%}$ \\
\hline
\end{tabular}

labialis $3(27.2 \%)$, Varicella zoster $02(18.1 \%)$ and Herpes genitalis $1(9.09 \%)$. The results were summarized in Table 9 and Figure 9.

\section{Inflammatory skin diseases categorization}

Out of 45 Inflammatory skin diseases, Eczema has been Indian Journal of Pharmacy Practice, Vol 13, Issue 1, Jan-Mar, 2020

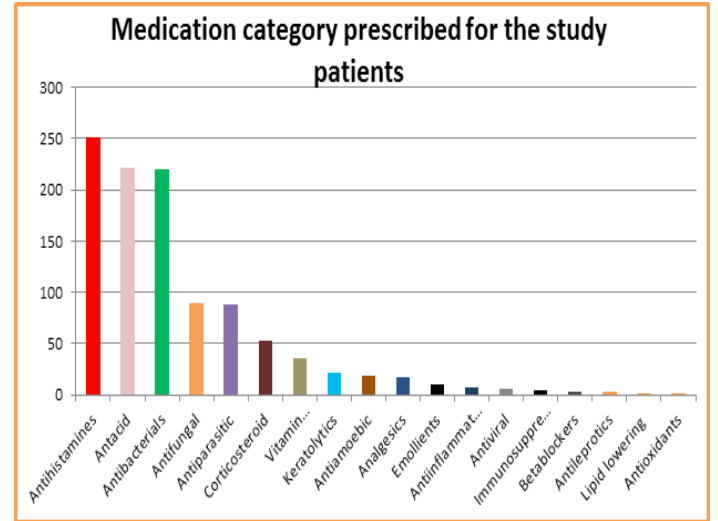

Figure 5: Medication categories prescribed for the study patient.

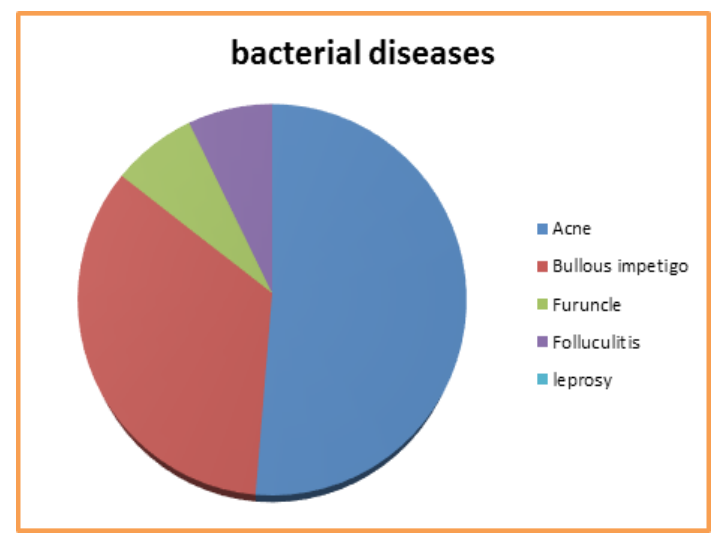

Figure 6: Bacterial diseases categorization.

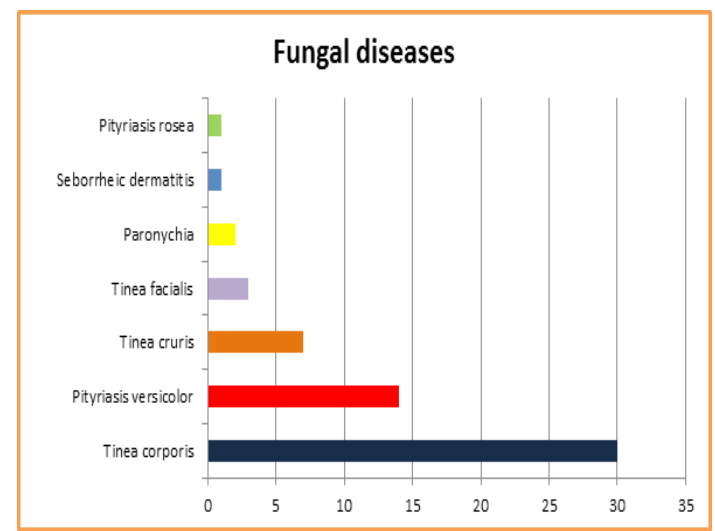

Figure 7: Fungal diseases categorization.

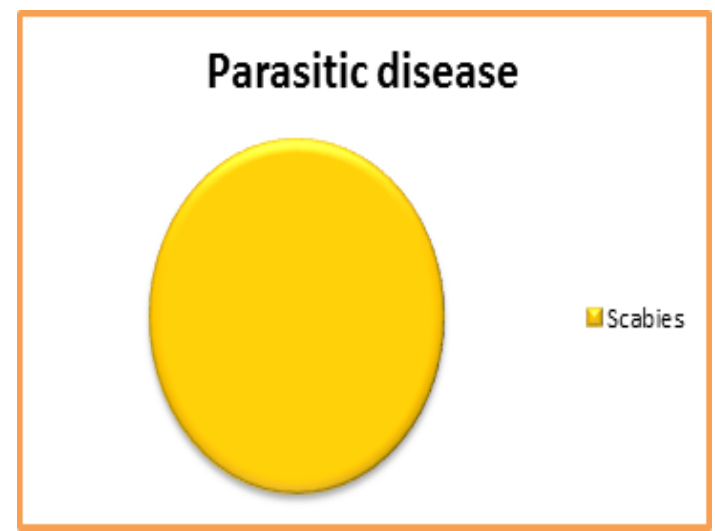

Figure 8: Parasitic diseases categorization. 


\begin{tabular}{|ccc|}
\hline \multicolumn{3}{|c|}{ Table 8: Parasitic diseases categorization. } \\
\begin{tabular}{ccc} 
Parasitic Disease & No. of cases & Percentage (\%) \\
\hline Scabies & 85 & $100 \%$ \\
\hline
\end{tabular}
\end{tabular}

\begin{tabular}{|c|c|c|}
\hline Viral Disease & No. of cases & Percentage (\%) \\
\hline Herpes zoster & 04 & $36.36 \%$ \\
\hline Herpes labialis & 03 & $27.2 \%$ \\
\hline Varicella & 02 & $18.1 \%$ \\
\hline Herpes genitalis & 01 & $9.09 \%$ \\
\hline Molluscum contagiosum & 01 & $9.09 \%$ \\
\hline Total & 11 & $100 \%$ \\
\hline
\end{tabular}

Table 10: Inflammatory skin diseases categorization.

\begin{tabular}{ccc} 
Inflammatory Skin Disease & $\begin{array}{c}\text { No. of } \\
\text { cases }\end{array}$ & Percentage (\%) \\
\hline Eczema & 23 & $51.1 \%$ \\
Prurigo nodularis & 11 & $24.4 \%$ \\
Contact dermatitis & 06 & $13.3 \%$ \\
Lichen simplex chronicus & 05 & $11.1 \%$ \\
Total & $\mathbf{4 5}$ & $\mathbf{1 0 0 \%}$ \\
\hline
\end{tabular}

Table 11: Pigmentary skin diseases categorization.

\begin{tabular}{ccc} 
Pigmentary skin Disease & No. of cases & Percentage (\%) \\
\hline Vitiligo & 05 & $71.4 \%$ \\
Epidermal nevus & 01 & $14.2 \%$ \\
Pityriasis alba & 01 & $14.2 \%$ \\
Total & $\mathbf{0 7}$ & $\mathbf{1 0 0 \%}$ \\
\hline
\end{tabular}

\section{Table 12: Photo dermatitis skin diseases}

\section{categorization.}

\begin{tabular}{ccc}
\hline $\begin{array}{c}\text { Photo dermatitis skin } \\
\text { Disease }\end{array}$ & $\begin{array}{c}\text { No. of } \\
\text { cases }\end{array}$ & Percentage (\%) \\
\hline Photo morphic light eruption & 01 & $33.3 \%$ \\
Actinic keratosis & 01 & $33.3 \%$ \\
Melasma & 01 & $33.3 \%$ \\
Total & $\mathbf{0 3}$ & $\mathbf{1 0 0 \%}$ \\
\hline
\end{tabular}

found to be highest in number, $23(51.1 \%)$ followed by Prurigo nodularis 11 (24.4\%), Contact dermatitis 06 (13.3\%) and Lichen simplex chronicus 05 (11.1\%). The results were summarized in Table 10 and Figure 10.

\section{Pigmentary skin diseases categorization}

Out of 7 Pigmentary skin diseases, Vitiligo has been found to be highest in number 05 (71.4\%) followed by Epidermal nevus 1 (14.2\%) and Pityriasis Alba 01 $(14.2 \%)$. The results were summarized in Table 11 and Figure 11.

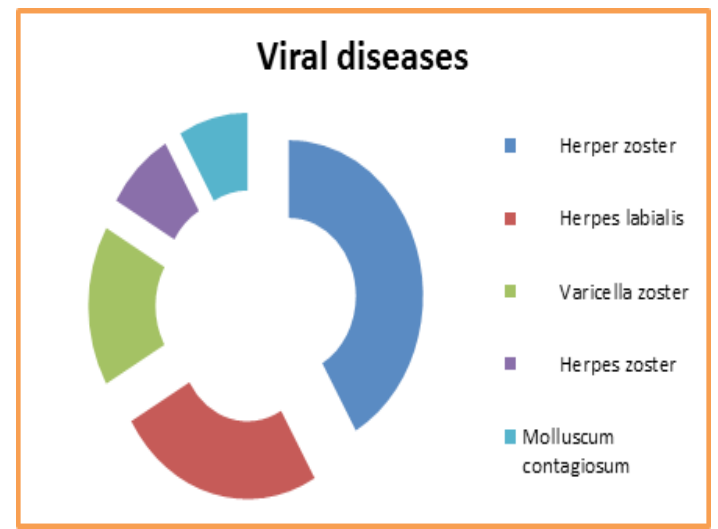

Figure 9: Viral diseases categorization.

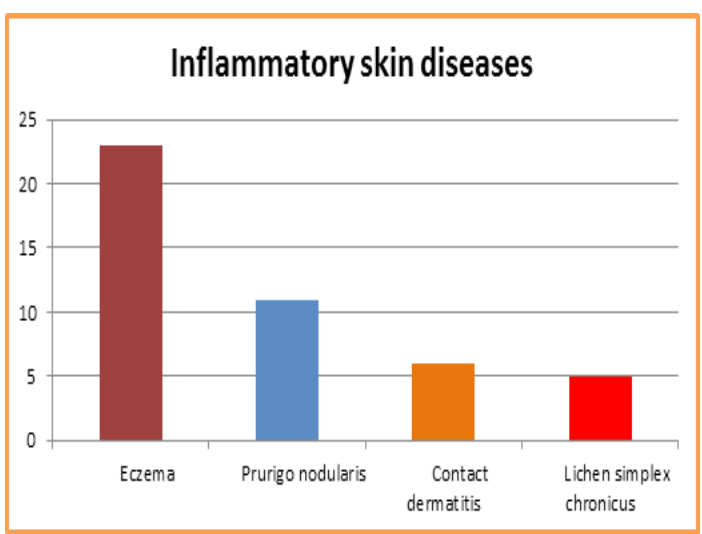

Figure 10: Inflammatory skin diseases categorization.

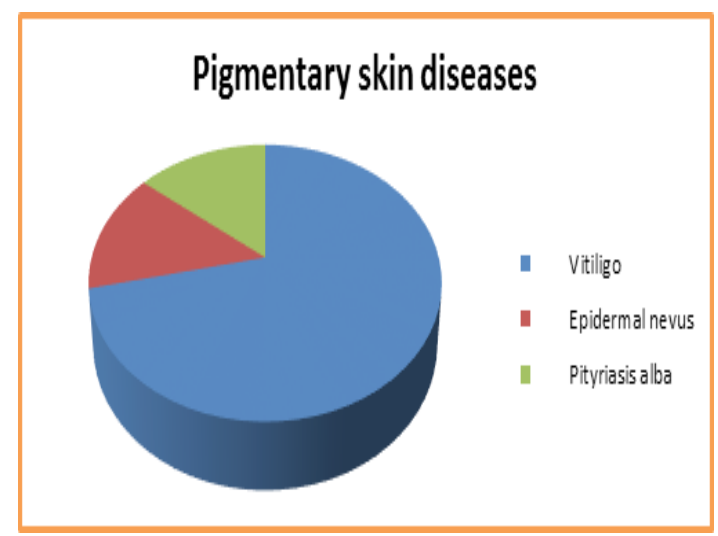

Figure 11: Pigmentary skin diseases categorization

\section{Photo dermatitis skin diseases categorization}

Out of 3 Photo dermatitis skin diseases, Photo morphic light eruption has been found to be $1(33.3 \%)$, Actinic keratosis 1 (33.3\%) and Melasma 1(33.3\%). The results were summarized in Table 12 and Figure 12.

\section{Allergic skin diseases categorization}

Out of 33 Allergic skin diseases, Urticaria has been found to be highest in number, 14 (42.4\%) followed by Pruritus 11 (33.3\%), Pyoderma 4 (12.1\%), Miliria crystalline 3 $(9.09 \%)$ and Bullous pemphigoid 1 (3.03\%). The results were summarized in Table 13 and Figure 13.

Indian Journal of Pharmacy Practice, Vol 13, Issue 1, Jan-Mar, 2020 
Table 13: Allergic skin diseases categorization.

\begin{tabular}{ccc} 
Allergic skin Disease & No. of cases & Percentage (\%) \\
\hline Urticaria & 14 & $42.4 \%$ \\
Pruritus & 11 & $33.3 \%$ \\
Pyoderma & 04 & $12.1 \%$ \\
Miliria crystallina & 03 & $9.09 \%$ \\
Bullous pemphigoid & 01 & $3.03 \%$ \\
Total & $\mathbf{3 3}$ & $\mathbf{1 0 0 \%}$ \\
\hline
\end{tabular}

Table 14: Autoimmune skin diseases categorization.

\begin{tabular}{ccc} 
Autoimmune skin Disease & No. of cases & Percentage (\%) \\
\hline Plantar keratoderma & 05 & $71.4 \%$ \\
Psoriasis & 02 & $28.5 \%$ \\
Total & $\mathbf{0 7}$ & $\mathbf{1 0 0 \%}$ \\
\hline
\end{tabular}

Table 15: Other type of skin diseases categorization.

\begin{tabular}{ccc}
\hline Other skin Disease & No. of cases & Percentage (\%) \\
\hline Lichen planus & 03 & $42.8 \%$ \\
Hemangioma & 02 & $28.5 \%$ \\
Keloid & 01 & $14.2 \%$ \\
Insect bite reaction & 01 & $14.2 \%$ \\
Total & $\mathbf{0 7}$ & $\mathbf{1 0 0 \%}$ \\
\hline
\end{tabular}

\section{Auto immune skin diseases categorization}

Out of 7 Auto immune skin diseases, plantar keratoderma has been found to be $5(71.4 \%)$ and Psoriasis has been found to be $2(28.5 \%)$. The results were shown in Table 14 and Figure 14.

\section{Other skin diseases categorization}

Out of 7 other skin diseases, Lichen planus has been found to be highest in number, 3 (42.4\%) followed by Hemangioma 2 (28.5\%), Keloid $1(14.2 \%)$ and Insect bite reaction $1(14.2 \%)$. The results were shown in Table 15 and Figure 15.

\section{DISCUSSION}

The study is evaluated according to age, sex, social class and disease. In our study, we have recruited 300 subjects of which male constitute 151(50.3\%) and females 149 $(49.7 \%)$. According to age group categorization, the patients in the age group of 11-20 were found to be maximum (20\%) following 0-10 age group (19\%). Based on social status, patients of middle status were found to highest (54\%) followed by low status (44\%). The total drugs used were 1053 in which Antihistamine where used in highest $(23.8 \%)$, while categorizing on disease conditions infectious diseases found to be in highest $(65.3 \%)$ followed by non-infectious diseases (34.6\%).

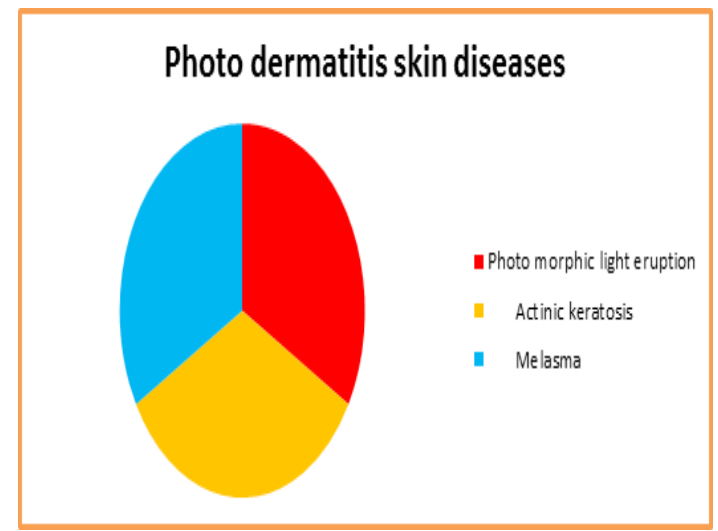

Figure 12: Photo dermatitis skin diseases categorization.

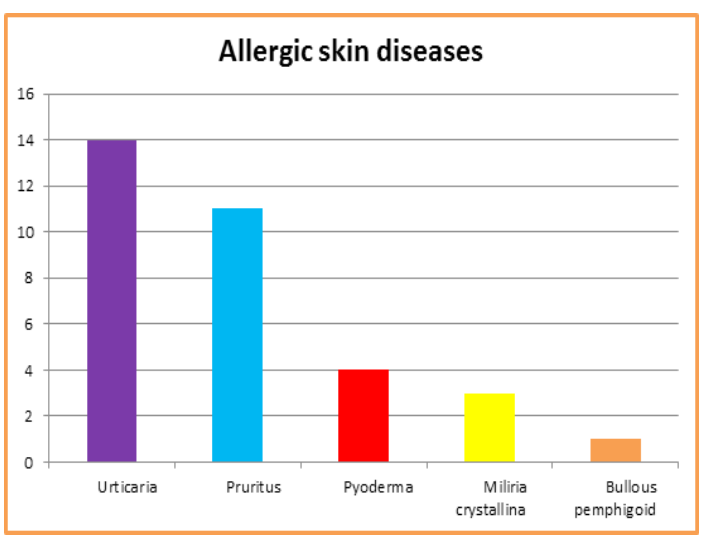

Figure 13: Allergic Skin Diseases Categorization.

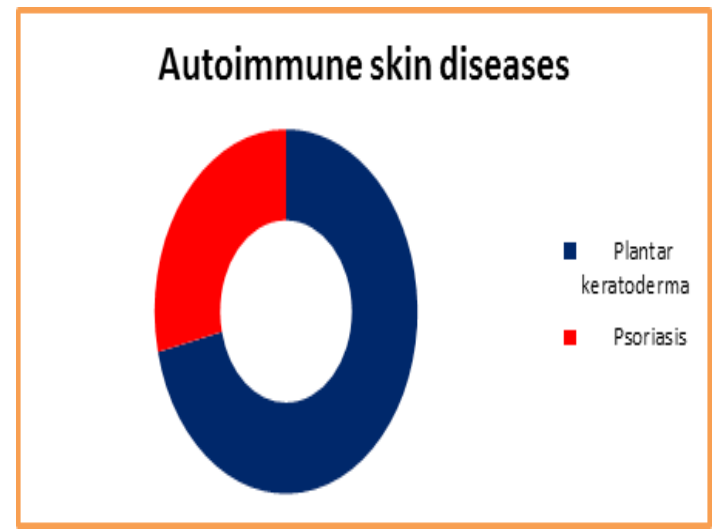

Figure 14: Autoimmune skin diseases categorization.

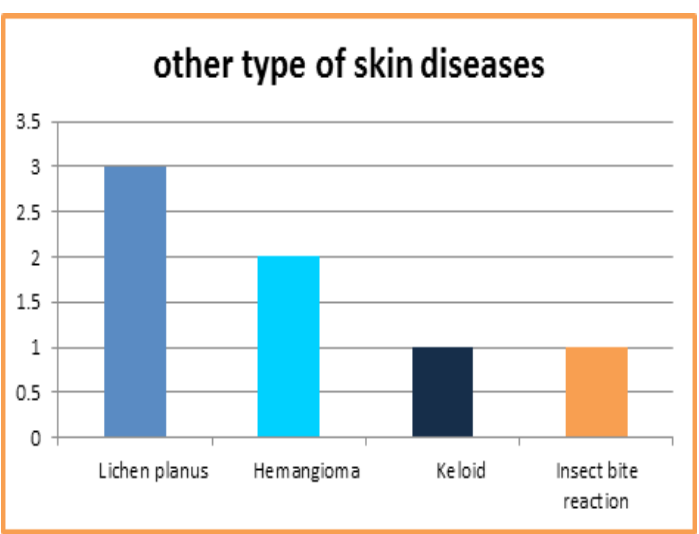

Figure 15: Other type of skin diseases categorization. 


\section{Class of drugs prescribed}

In our study, Anti-histamines were mainly prescribed in almost every prescription. Among the anti-histamines, chlorpheniramine maleate is the only drug prescribed.

Among Antacids, Ranitidine is used in maximum number (98.6\%) followed by pantoprazole (1.3\%).

Among Antibacterials, Amoxycillin is used in highest number (50.4\%) followed by doxycycline (24\%), soframycin topical (10.4\%), ciprofloxacin (9\%), ampicillin $(2.2 \%)$, clindamycin topical (1.8\%) and gentamycin (1.3\%).

Among Antifungals, Ketokonazole topical is used in maximum number $(67.4 \%)$ followed by candid cream $(58.4 \%)$, fluconazole tablet $(29.2 \%)$ and terbinafine $(3.3 \%)$.

Among Antiparasitic drugs, Benzyl benzoate is used highest number $(94.3 \%)$ followed by ivermectin $(3.4 \%)$ and permethrin (2.2\%). Among Antivirals, only Acyclovir is used.

Among Corticosteroids, Prednisolone is used in maximum number $(54.7 \%)$ followed by mometasone $(22.6 \%)$, betamethasone $(5.6 \%)$, halobetasol $(5.6 \%)$, clobetasol $(5.6 \%)$, hydrocortisone $(5.6 \%)$.

Among Immunosuppressant's, Tacrolimus is used in maximum number $(75 \%)$ followed by neotrexate $(25 \%)$.

Among Keratolytics, Whitfield ointment is used in highest number $(77.2 \%)$ followed by salicylic acid $(22.7 \%)$. Among Antiamoebics, only Metronidazole is used.

Among Analgesics, Paracetamol is used in highest number $(47 \%)$ followed by diclofenac $(35.2 \%)$ and dicyclomine $(17.6 \%)$. Among Anti-inflammatory drugs, Prophysalic NF 6 cream is used.

Among Vitamin supplements, Vit. A and D is used in highest number (58.3\%) followed by Vit. B (38.8\%) and multivitamin $(2.7 \%)$.

Among sulphone drugs, only Clofazamine is used. Among emollients, only Calamine lotion is used. Among Betablocker drugs, only Timolol eye-drops are used.

The prescriptions in our study mentioned mostly generic names of the drugs. Strength of the drugs was mentioned and quantity required was mentioned in all the prescriptions. Instructions regarding the use of topical preparations were mentioned and duration of treatment was mentioned in of the prescriptions in our study. Appropriate health education is vital in combating their spread, reducing the associated morbidity and improving the health status of the population. Dermatologists use drugs to treat patients successfully.

The proportion of infectious diseases was more among those who have not maintained their personal hygiene. Frequency and duration of administration was specified in majority of prescriptions for topical administered drugs which shows quite rational prescribing and dose/strength was specified in prescriptions and the prescribing pattern should be improved to avoid prescription errors while dispensing the medication by a pharmacist to be followed in the OPD for better patient care. The preponderance of scabies can be due to their close contact with children, less maintenance of hygiene and shared objects. Scabies also shows strong association with history in other family members. This throws light on need of community-wide attention, in contrast to personalized treatment, to get control over this problem. Besides this, water inadequacy is strongly associated with skin infections as well as with scabies.

\section{CONCLUSION}

The major skin diseases identified from our study were scabies, tinea corporis, eczema, acne and urticaria in which male patients were more susceptible. The prevention of skin diseases necessitates a need for better health education, improved hygiene and good living standards. Public resources should make people aware of skin diseases and their preventive measures. So that we can reduce the burden of skin diseases in our society. According to the analyzed results and the conclusions made are; skin disease in one of the major health issue which affects the daily livelihood of human kind. Assessment of drug usage and quality of life will bring awareness with respect to diseases and improve the quality of life. So, such studies should be carried out on continuous basic. Skin diseases specially the skin infections like scabies are commonly seen in younger age group; the age bears an indirect relationship with occurrence of this problem. Among the non-infectious skin involvement, the allergic diseases are very commonly seen in all strata of the population. Bad hygiene practice and inadequacy of water are strongly associated with infectious skin diseases.

\section{Ethical Approval}

The study was approved by the Institutional Review Board of Browns College of Pharmacy and Ethical committee of Government Hospital, Khammam.

Indian Journal of Pharmacy Practice, Vol 13, Issue 1, Jan-Mar, 2020 


\section{ACKNOWLEDGEMENT}

The authors would like to thank the management and staff members and ethical committee members of Browns College of Pharmacy and Ethical committee of Government Hospital, Khammam, Telangana, India.

\section{CONFLICT OF INTEREST}

The authors declare no Conflict of Interest.

\section{ABBREVIATIONS}

OPD: Outpatient Department.

\section{SUMMARY}

- Skin disease in one of the major health issues which affects the daily livelihood of human kind.

- The major skin diseases identified from our study were scabies, tinea corporis.

- Male patients were found to be more susceptible.

- Among Antibacterials Amoxycillin (50.4\%), Antifungals Ketokonazole topical (67.4\%), Antiparasitic drugs Benzyl benzoate is used highest number (94.3\%) are most widely used.

- Bad hygiene practice and inadequacy of water are strongly associated with infectious skin diseases.

\section{REFERENCES}

1. Joel JJ, Jose N, Shastry CS. Patterns of Skin Disease and Prescribing Trends in Rural India. Schol Acad J Pharm. 2013;2(4):304-9.
2. Schofield OMV, Hunter JAA. Diseases of the skin in Davidson's Principles and Practice of Medicine. 21 ${ }^{\text {st }}$ Edition. 2011.

3. Clark RA, Ghosh K, Tonnesen MG. Journal of Investigative Dermatology. 2007;127:1018-29.

4. Engman MF. The Skin: A Mirror to the System. JAMA. 1919;73(21):1565-8.

5. Das KK. Pattern of dermatological diseases in Guwahati Medical College and hospital Guwahati. Indian J Dermatol Venereol Leprol. 2003;69(1):16-8.

6. Rao GS, Kumar SS, Sandhya. Pattern of skin diseases in an Indian village. Indian J Med Sci. 2003;57(3):108-10.

7. Abbas Z, Hoseen M. Prevalence of skin diseases in hamedan, Iran in 2002. Indian J Dermatol WB. 2005;50(4):208-11.

8. Atraide DD, Akpa MR, George IO. The Pattern of Skin disorders in a Nigerian Tertiary Hospital. J Public Health Epidemiol. 2011;3(4):177-81.

9. Bijayanti D, Zamzachin G. Pattern of skin diseases in Imphal. Indian J Dermatol. 2006;51(2):14950.

10. Soumerai S. Factors influencing prescribing. The Australian Journal of Hospital Pharmacy. 1988;18(3):9-16.

11. Hogerzeil HV. Promoting rational prescribing: an international perspective. $\mathrm{Br} \mathrm{J}$ Clin Pharmacol. 1995;39(1):1-6.

12. Divyashanthi CM, Nandhini A, Kumar SA. Study on drug utilization pattern of antibiotics among dermatology in-patients of a tertiary care teaching hospital, Karaikal, Puducherry. Int J Basic Clin Pharmacol. 2014;3(6):1072-7.

13. Chon SY, Doan HQ, Mays RM, Singh SM, Gordon RA, Tyring SK. Antibiotic overuse and resistance in dermatology. Dermatologic Therapy. 2012;25(1):5569.

14. Abebaw T. Prescribing Pattern for Skin Diseases in Dermatology OPD of in Boru Meda Hospital, North East, Ethiopia. Journal of Basic and Clinical Pharmacy. 2018;9(1):31-3.

15. Chester BG. Polypharmacy in elderly patients with diabetes. Diabetes Spectrum. 2002;15(4):240-8.

16. Michael JC, John T, Catherine H, Julie C, Victoria B, Rachid TA. An audit of adverse drug reactions to aqueous cream in children with atopic eczema. The Pharmaceutical Journal. 2003;271(7277):747-8.

17. https://www.who.int/topics/infectious_diseases/en/. 